\title{
A RARE CASE OF HETEROTOPIC SECONDARY ABDOMINAL PREGNANCY FOLLOWING EXPULSION OF FOUR FOETUSES
}

\author{
Rekha Wadhwani, Juhi Agarwal, Deepti Gupta, Sudha Chaurasia, Raksha Bamnia
}

1. Associate Professor, Department of Obstetrics \& Gynaecology, Sultania Zanana Hospital, Gandhi Medical College, Bhopal.

2. Assistant Professor, Department of Obstetrics \& Gynaecology, Sultania Zanana Hospital, Gandhi Medical College, Bhopal.

3. Assistant Professor, Department of Obstetrics \& Gynaecology, Sultania Zanana Hospital, Gandhi Medical College, Bhopal.

4. Associate Professor, Department of Obstetrics \& Gynaecology, Sultania Zanana Hospital, Gandhi Medical College, Bhopal.

5. Assistant Professor, Department of Obstetrics \& Gynaecology, Sultania Zanana Hospital, Gandhi Medical College, Bhopal.

\section{CORRESPONDING AUTHOR}

Dr. Rekha Wadhwani, IV/6, ESI Hospital Campus, Sonagiri, C- Sector, Raisen Road, BHEL, Bhopal, M.P. 462021.

E-mail: drrekhaw@yahoo.co.in, deeptireja@gmail.com

Ph: 00919893019091,00919827267464

ABSTRACT: Heterotopic pregnancy is rare and its continuation as secondary abdominal pregnancy is even rarer. A patient who had received ovulation induction presented with history of expulsion of four foetuses followed by abdominal distension and pain in abdomen. Ultrasound was suggestive of rudimentary horn pregnancy. She was kept on conservative management and at 33 weeks, emergency laparotomy was done. She had secondary abdominal pregnancy without hemoperitoneum, receiving vascular supply from ruptured rudimentary horn. Rudimentary horn was removed and patient was discharged successfully with live and healthy baby.

KEY WORDS: quintuplets, secondary abdominal pregnancy, heterotopic pregnancy

INTRODUCTION: Heterotopic pregnancy is very rare with incidence of about 1 in $30,000^{1}$. This incidence increases with ovulation induction and becomes very high with Assisted reproductive techniques. Abdominal pregnancy is also a rare event with reported frequency of about 1 in 10,000 to 1 in 100,000 live births ${ }^{2}$. Here we report a rare case of heterotopic pregnancy with quintuplets which continued as secondary abdominal pregnancy.

CASE REPORT: A 20 year old primigravida was admitted on $2^{\text {nd }}$ march 2008 as a referred case with history of spontaneous abortion of quadruplets one and half month back followed by continuous pain in abdomen and abdominal distension. She had a history of spontaneous expulsion of quadruplets at civil hospital one and half month back. This was followed by abdominal distension, persistence of amenorrhea and pain in abdomen.

The woman had been married for only 9 months and just after 2 months of her marriage she had received some oral medication to help her conceive. Patient did not have any records of that treatment. Following this treatment, she became pregnant. However she did not go for any 


\section{CASE REPORT}

antenatal checkups. Apart from this, she did not have any significant medical, surgical, personal or family history.

At 6 months gestation, she developed pain in abdomen for which she went to civil hospital, Vidisha. There she spontaneously aborted 4 fetuses of 500 gms each. Thereafter she was discharged. However her amenorrhea persisted, abdominal distension increased and it was associated with pain in abdomen. She again went back to civil hospital Vidisha, where ultrasound was done which showed empty uterine cavity with possibility of rudimentary horn pregnancy. She was then referred to tertiary care centre.

On admission at our institute, her general condition was stable, pallor was present. On per abdomen examination, uterine contour could not be made out, fetal parts were very superficial and fetal heart sounds were regular. On per vaginum examination, exact uterine size could not be made out, cervix was soft and closed and bilateral fornices were free. Repeat ultrasound was done which showed cornual pregnancy of 28 weeks with severe oligohydramnios. A diagnosis of rudimentary horn pregnancy with possibility of secondary abdominal pregnancy with single live fetus of 28 weeks was made. Since patient was fulfilling the martin's ${ }^{3}$ criteria of continuation of abdominal pregnancy and was keen on continuing, decision for conservative management was taken.

All her routine investigations were within normal limits. Fetal growth was monitored clinically and with serial ultrasounds. At 33weeks, patient developed severe abdominal discomfort, she had tachycardia. Emergency Laparotomy had to be done.

OPERATIVE FINDINGS: There was no hemoperitoneum and the fetus was lying inside intact pseudo sac. Female baby of $2.5 \mathrm{~kg}$ was delivered. Placenta was found attached to the rudimentary horn on left side which was a non-communicating horn. Placenta and ruptured rudimentary horn were removed. Baby's APGAR score was satisfactory. Patient stood the procedure well and her postoperative period was also uneventful. She was discharged on $10^{\text {th }}$ postoperative day with healthy baby.

DISCUSSION: Heterotopic pregnancy is otherwise a rare entity in patients with spontaneous conception. But in patients receiving ovulation induction, the incidence increases manifold. Thus Ovulation induction has its own complications and hence it should be used judiciously and only when indicated. Patients conceiving after induction of ovulation should be counseled about importance of antenatal checkup, ultrasound and followed up meticulously.

Abdominal pregnancy also though rare should be kept in mind especially if there is history of infertility, assisted reproductive technique, persistent pain in abdomen36, persistent malpresentation. Diagnosis of abdominal pregnancy can be missed even on ultrasound, hence every clinician should have high index of suspicion. If a patient with amenorrhea has persistent abdominal pain, gastrointestinal disturbances, painful fetal movements, ill defined uterine contour, displaced cervix and abnormal presentations; abdominal pregnancy should be ruled out. Ultrasound criteria suggested by Allibone ${ }^{5}$ can be used for diagnosis of abdominal pregnancy. These include 1) demonstration of a fetus in a gestational sac outside the uterus; 2 ) failure to visualize the uterine wall between the fetus and urinary bladder; 3) close proximity between the fetus and the anterior abdominal wall; and 4) localization of the placenta outside the confines of the uterine cavity. Since the maternal and perinatal mortality is very high, about $0.5-18 \%$ and $40-95 \%$ respectively 4 ; hence careful evaluation and planning is needed at a well equipped centre. And if a patient fulfils the martins criteria ${ }^{3}$, she can be given an option to 
continue her abdominal pregnancy. Treatment of abdominal pregnancy is mainly surgical and the main controversy remains whether or not to remove the placenta. If the blood supply can be identified and ligated safely then the placenta should be removed otherwise left in situ and patient followed up. In our case since the placenta was getting its blood supply from the noncommunicating rudimentary horn, hence it could be removed safely.

CONCLUSION: Abdominal pregnancy is a rare and potentially fatal complication. Hence a high index of suspicion is required.

\section{REFERENCES:}

1. Govindarajan MJ and Rajan R. Heterotopic pregnancy in natural conception. J Hum Reprod Sci. 2008 Jan-Jun; 1(1): 37-38.

2. Morita R, Tsusumi O, Kuramochi K et al.Successful laparoscopic management of primary abdominal pregnancy. Hum Reprod 1996; 11:2546-7

3. Faller $\mathrm{E}$ and Kauffmann $\mathrm{E}$ et al. Abdominal pregnancy carried to term. Journal of Obstetrics and Gynecology and Reproductive Biology. Nov 2006; 35(7): 732-735

4. Martin JN Jr, Sessums JK, Martin RW et al. Abdominal pregnancy: current concepts of management. Obstet Gynecol 1988; 71: 549-57.

5. Allibone GW, Fagan CJ, Porter SC. The sonographic features of intra-abdominal pregnancy.J Clin Ultrasound. 1981 Sep;9(7):383-7.

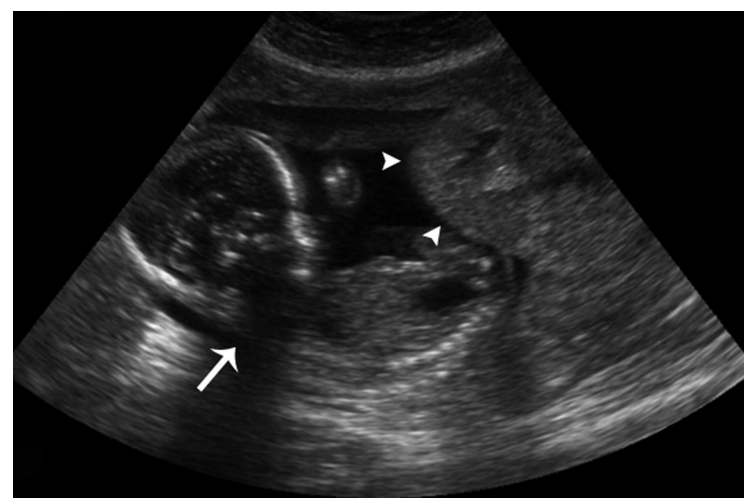

Ultrasound image showing the abdominal pregnancy after 4 fetuses had aborted

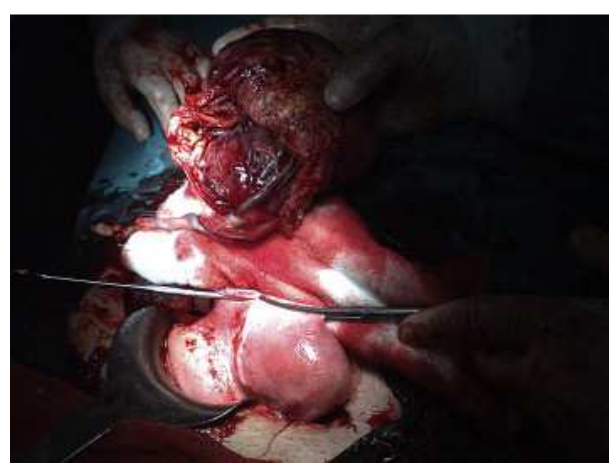

Per- operative image showing ruptured rudimentary horn with placenta. 